\title{
Evaluation of Metal Exposure at a Nanoparticle Research and Development Company
}

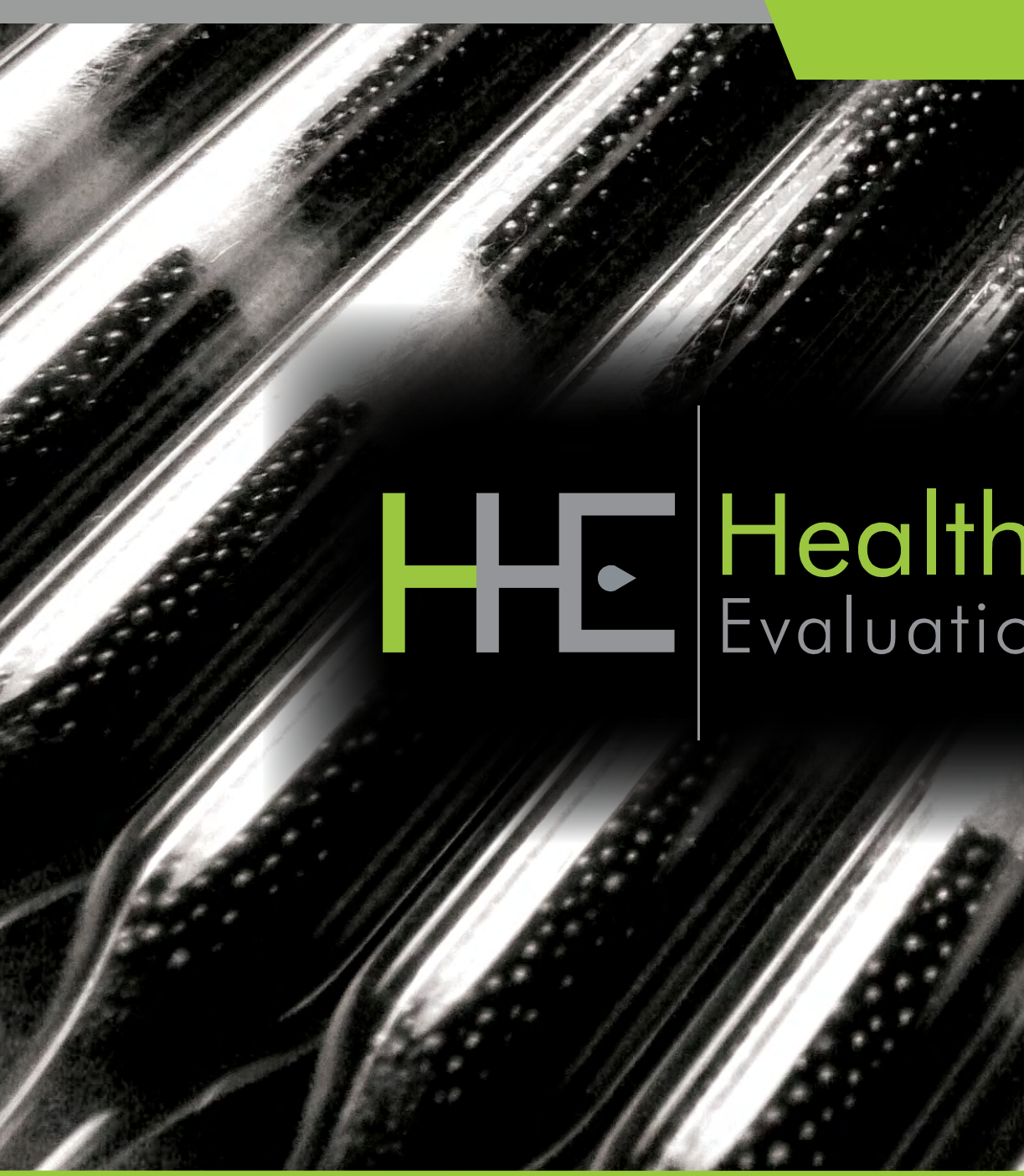

\section{James Couch MS, CIH, CSP, REHS/RS Elena Page MD, MPH}

Kevin L. Dunn, MS, CIH

HHE Report No. 2014-0207-3248 March 2016

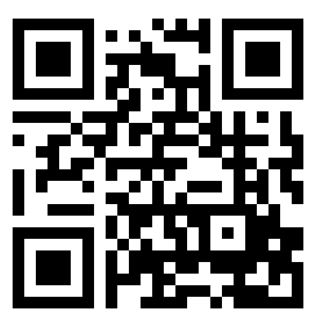

U.S. Department of Health and Human Services Centers for Disease Control and Prevention National Institute for Occupational Safety and Health

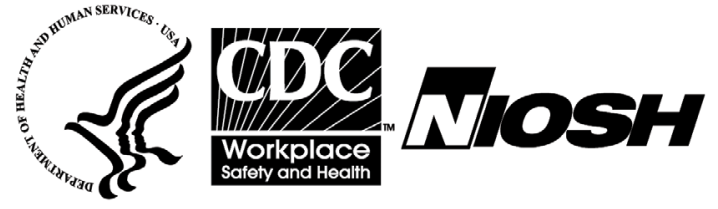




\section{Contents}

Highlights.

Abbreviations ................................... iii

Introduction ............................................ 1

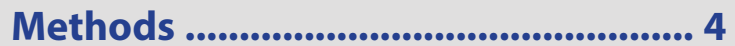

Results and Discussion ........................ 5

Conclusions ........................................ 10

Recommendations........................... 10

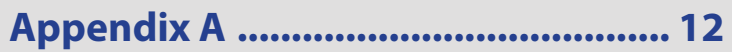

Appendix B .................................. 17

References ...................................... 20

Acknowledgements......................... 23

The employer is required to post a copy of this report for 30 days at or near the workplace(s) of affected employees. The employer must take steps to ensure that the posted report is not altered, defaced, or covered by other material.

The cover photo is a close-up image of sorbent tubes, which are used by the HHE Program to measure airborne exposures. This photo is an artistic representation that may not be related to this Health Hazard Evaluation. Photo by NIOSH. 


\section{Highlights of this Evaluation}

The Health Hazard Evaluation Program received a request from employees at a nanotechnology research and development company. The company used a metal alloy for several months without knowing it contained beryllium. They stopped using the alloy and hired a contractor to investigate. The contractor found the potential for beryllium exposure to be low. Employees were still concerned about exposure to beryllium and other metals.

\section{What We Did}

- We evaluated the workplace in December 2014.

- We collected 40 surface wipe samples to check for the presence of beryllium and other metals.

- We took four air samples to analyze for metals and their particle size characteristics.

- We interviewed current and former employees. We asked about their health and possible workrelated medical conditions.

- We used a specialized blood test to test seven employees and one former employee for beryllium sensitization.

\section{What We Found}

- Surface wipe samples showed the presence of several metals in production and nonproduction areas. The samples contained chromium, nickel, cobalt, titanium, iron, cadmium, and beryllium.

- Air samples had no detectable beryllium. We

We evaluated exposure to beryllium and other metals at a nanotechnology research and development company. We also tested employees for beryllium sensitization. No employees we tested were sensitized to beryllium. Beryllium and other metals were present on surfaces in some production and nonproduction areas. did find very small amounts of chromium, iron, nickel, and titanium.

- Employees did not report health problems related to work. We identified no medical issues consistent with chronic beryllium disease.

- No employees we tested were sensitized to beryllium.

\section{What the Employer Can Do}

- Train employees on how to prevent the transfer of metals from production areas to nonproduction areas.

- Review operating and housekeeping procedures. Look for ways to prevent metals from getting into nonproduction areas.

- Evaluate use of tacky mats, disposable booties, or shoe change stations at the production area exits to reduce the amount of metal that moves into the non-production areas.

- Add a barrier or modify the wall to separate the spark plasma sintering room from the neighboring company's production floor. 
- Repair uneven walking surfaces in the cryomilling area.

\section{What Employees Can Do}

- Follow standard operating procedures for personal protective equipment. This includes gloves, a respirator, and a laboratory coat.

- Tell your doctor you may have been exposed to beryllium and give him or her a copy of your test results.

- If you develop respiratory symptoms, chest or joint pains, or chronic lung disease, notify your healthcare provider that you may have been exposed to beryllium. 


\section{Abbreviations}

$\begin{array}{ll}\mu \mathrm{g} / 100 \mathrm{~cm}^{2} & \text { Micrograms per 100 square centimeters } \\ \mu \mathrm{g} / \mathrm{m}^{3} & \text { Micrograms per cubic meter } \\ \mu \mathrm{g} / \mathrm{sample} & \text { Micrograms per sample } \\ \mathrm{BeLPT} & \text { Beryllium lymphocyte proliferation test } \\ { }^{\circ} \mathrm{C} & \text { Celsius } \\ \mathrm{cc} & \text { Cubic centimeter } \\ \mathrm{CFR} & \text { Code of Federal Regulations } \\ \mathrm{Cr} & \text { Elemental chromium } \\ \mathrm{Cr}(\mathrm{VI}) & \text { Hexavalent chromium } \\ \mathrm{DOE} & \text { Department of Energy } \\ \mathrm{IARC} & \text { International Agency for Research on Cancer } \\ \text { LOD } & \text { Limit of detection } \\ \text { LOQ } & \text { Limit of quantitation } \\ \mathrm{MDC} & \text { Minimum detectable concentration } \\ \mathrm{MQC} & \text { Minimum quantifiable concentration } \\ \mathrm{ND} & \text { Not detected } \\ \mathrm{NIOSH} & \text { National Institute for Occupational Safety and Health } \\ \mathrm{OEL} & \text { Occupational exposure limit } \\ \mathrm{p} / \mathrm{cc} & \text { Particles per cubic centimeter } \\ \text { PPE } & \text { Personal protective equipment } \\ \text { SDS } & \text { Safety data sheet } \\ \text { SPS } & \text { Spark plasma sintering }\end{array}$


This page left intentionally blank 


\section{Introduction}

The Health Hazard Evaluation Program received a request from employees at a nanotechnology research and development company. The safety data sheet (SDS) for an alloy used by the company did not list beryllium but the company learned from the supplier that the alloy contained trace amounts of beryllium. For mixtures or composites, the SDS does not have to list components that are less than 1 percent ( 0.1 percent if a carcinogen) [OSHA 2016]. The company discontinued using the alloy because they did not have an appropriate beryllium control plan. They hired a contractor to investigate the potential for beryllium exposure. The contractor determined that potential beryllium exposure was low. Employees were still concerned so they submitted the health hazard evaluation request. We visited the facility in December 2014.

Our evaluation focused on beryllium in two production areas that used the berylliumcontaining alloy (cryomill and spark plasma sintering [SPS]) and the office area.

The company had seven employees, and all worked in the cryomilling and SPS areas. Because the company had experienced a downturn in orders and production, typical work activities were limited during our evaluation.

\section{Cryomilling}

Although the cryomills were not in use during our site visit, we reviewed the process to understand typical work practices and potential health hazards. Cryomilling uses mechanical grinding at low temperatures, commonly with liquid nitrogen, to increase the material's brittleness. This process decreases the pulverized material's particle size, often to nanoparticle size. The company typically uses the cryomill process for a range of materials including metals, alloys, ceramics, and carbides. The facility has two cryomills, which employees refer to as either the "old" or the "new" cryomill (Figure 1). A trailer on the facility's property houses the cryomills. The trailer's ventilation system is separate from that

of the main building. 


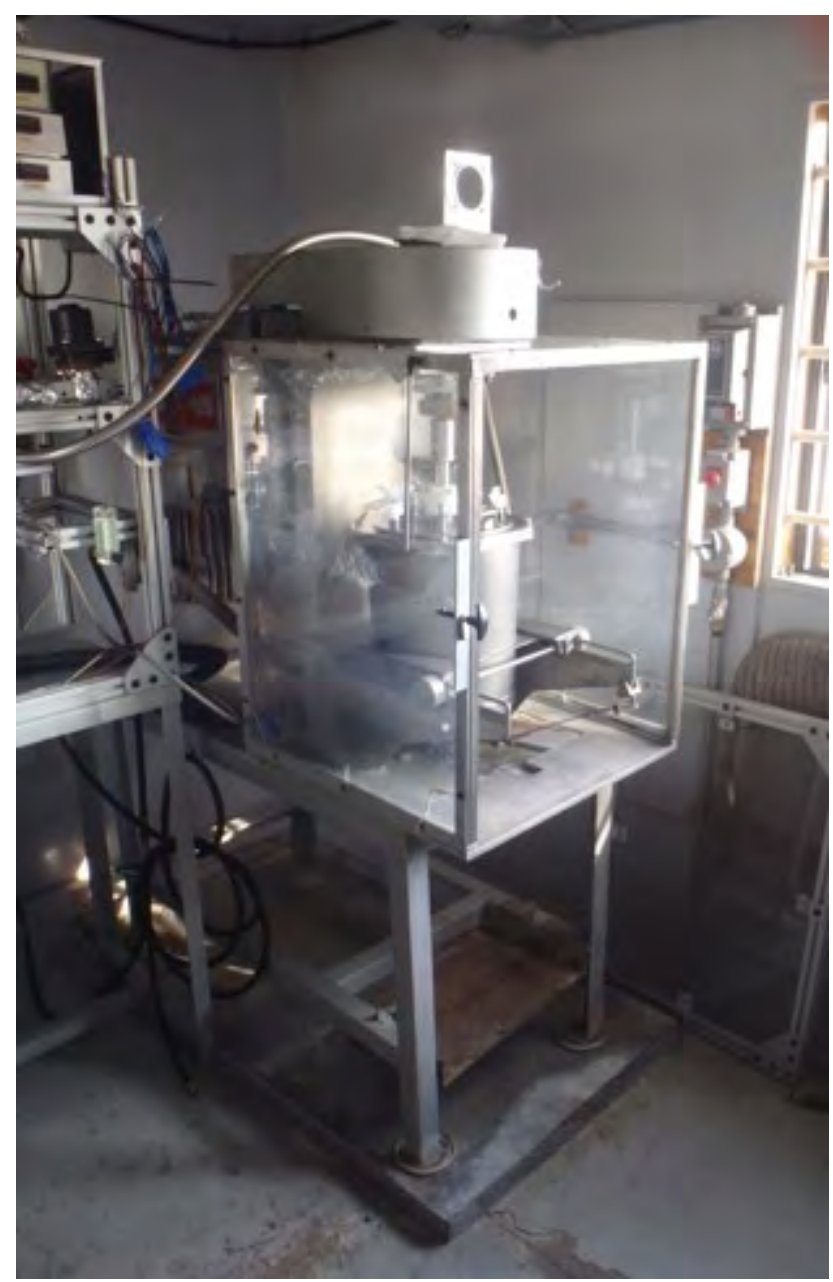

Figure 1. Cryomill inside an enclosure. Photo by NIOSH.

Employees operating cryomills load metal powders or chips by hand tools, such as scoops, into the cryomill and perform start-up procedures. Employees remain in the cryomilling production area to monitor the process and adjust the machine settings as needed.

Cryomilling operating times typically range from a few hours to more than 12 hours. After obtaining the specified particle size, the operator removes the product using hand tools and places it into a sealed container. The product is transferred from the cryomill to the sealed container at the face of the enclosure.

\section{Spark Plasma Sintering}

In the SPS process, an electrical spark discharge creates temperatures up to 10,000 degrees Celsius $\left({ }^{\circ} \mathrm{C}\right)$ to form thermal and electrolytic bonds between metal powders [Fuji 2016]. The SPS machine allows for the same process as in traditional sintering but at temperatures $200^{\circ} \mathrm{C}-500^{\circ} \mathrm{C}$ lower and processing times 5-20 minutes less. More information can be found on the manufacturer's website [Fuji 2016].

The SPS machine, die prep and press, glove box, and slow saw were on the first floor (Figure 2). The SPS machine was equipped with a custom local exhaust ventilation hood and system 
that moved exhausted air through a high efficiency particulate air filter and exhausted it outside. To operate the SPS, the employee prepared a metal powder alloy (aluminum 6061) inside the glove box and on the die preparation table. Aluminum 6061 typically consists of more than $95 \%$ aluminum by weight. Liquid nitrogen injected to ensure product quality kept the glove box under positive pressure. The room had general dilution ventilation. Besides beryllium, the alloy contains chromium, copper, iron, magnesium, manganese, tin, titanium, and zinc with other trace metals. The employee loaded the alloy into the sintering die in the glove box and moved the die to the die preparation table. He then placed the sintering die into the die press to compress the metal powders. After compression, he placed the sintering die into the SPS machine. After removing the die from the SPS machine, he deburred the cast into a finished product.

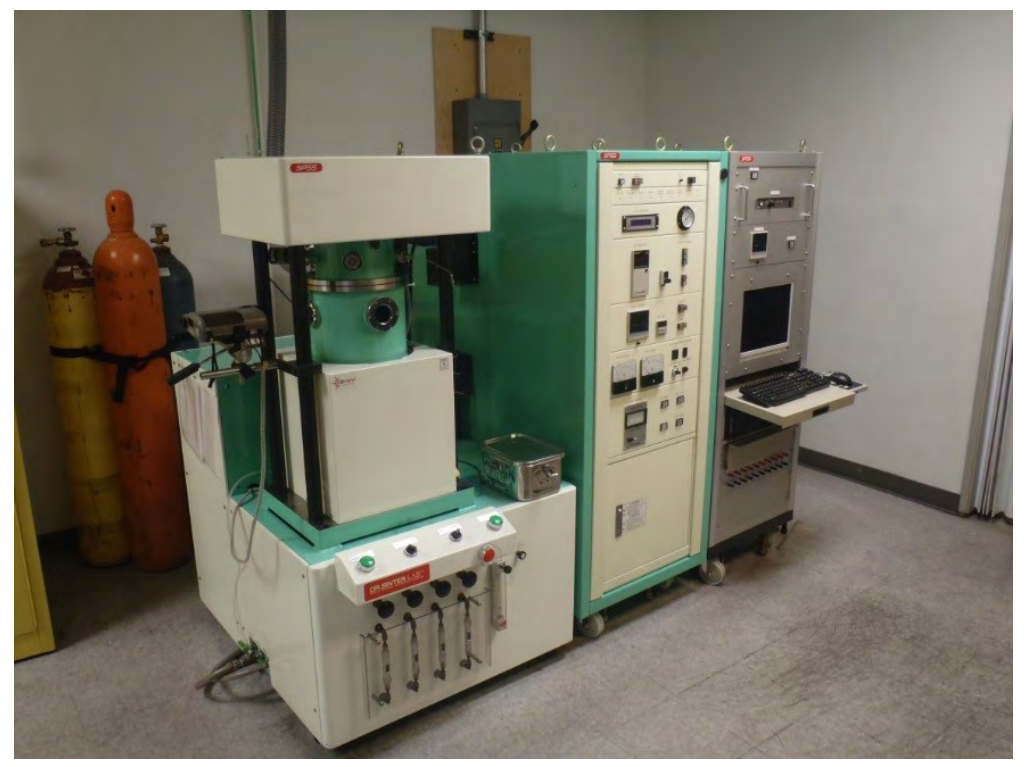

Figure 2. Photo of the SPS machine used for metal powder sintering. Photo by NIOSH.

During the SPS process, the employee wore a half-mask elastomeric respirator with a combination cartridge (P100/organic vapor/acid gas). The employee also wore a laboratory coat, safety glasses, and nitrile gloves for all tasks observed.

Another company, which manufactured and machined metal parts using metalworking fluids, shared the building's first floor. The SPS room was directly adjacent to the other company's production area. We observed numerous locations where air from the metal part production area could enter the SPS room. Due to the openings in the wall between the SPS room and the adjacent company, air entering into the SPS room may contain metalworking fluids and other hazards from the metal processing operations.

\section{Second Floor}

The second floor contained individual offices, cubicles, a conference room, and a storage area. Employees who worked in production areas routinely used these areas. The production area and the second floor were on separate ventilation systems. 


\section{Methods}

The main objectives of this evaluation were to determine if beryllium was present in the workplace and if employees were sensitized to beryllium. We collected surface wipe samples and personal and area air samples. We observed workplace conditions and work processes and practices. We interviewed employees about their medical status and offered the blood beryllium lymphocyte proliferation test (BeLPT) to current and former employees. This blood test measures sensitivity to beryllium. It is very specific to determine if a person has an allergic reaction to beryllium. Other objectives included assessing the potential for inadvertent transport of contaminants from production to non-production areas and evaluating the potential for nanoparticle generation during the SPS process.

\section{Surface and Air Sampling for Beryllium and other Elements}

We collected 40 surface wipe samples for beryllium and other elements using 15 centimeter x 15 centimeter GhostWipes (Environmental Express) premoistened with deionized water. The surface wipe samples were collected and quantitatively analyzed according to National Institute for Occupational Safety and Health (NIOSH) Method 9102 [NIOSH 2016]. We collected surface wipe samples in production areas (on high and low contact surfaces) and non-production areas (office and cubicle areas). NIOSH Method 9102 provided analytical concentrations for 23 metals (plus the nonmetal, selenium). Some of these 23 metals were not used in the facility.

We collected two air samples (one personal and one area) for elements using NIOSH Method 7303, with modification [NIOSH 2016]. The modification included wiping the interior of the filter cassette with a mixed cellulose ester filter to collect particles on the inside walls. This approach is consistent with the NIOSH recommendation that all particles entering the sampler be included as part of the sample whether they deposit on the filter or on the inside surfaces of the sampler [NIOSH 2016]. We analyzed the mixed cellulose ester filter along with the sample filter [NIOSH 2016].

We also collected two air samples (one personal and one area) for respirable particles using a modified NIOSH Method 7402 [NIOSH 2016]. The modifications to NIOSH Method 7402 included eliminating the asbestos identification steps. We analyzed particles by transmission electron microscopy with energy dispersive spectroscopy to indicate the relative abundance of nanostructures per cubic centimeter (cc) of air, as well as other particle characteristics such as size, shape, chemical composition, and degree of agglomeration. All of the air samples were task-based, collected during the only die prep and SPS operations done during our visit (less than 2 hours total duration). The employee spent most of the task-based sampling time in the SPS room performing die prep and sintering. The employee also did deburring and finishing work in an adjacent room for approximately 10 minutes. The area air sample was collected in the SPS room near the SPS machine.

We also used TSI model 3007 handheld condensation particle counters to characterize process emissions in the SPS room and compare them to a nonproduction area. We selected 
the second floor conference room to represent the nonproduction area. The SPS room and the nonproduction area were on separate ventilation systems.

\section{Workplace Conditions}

We evaluated the general cleanliness of the facility, proper use of personal protective equipment (PPE), metal and other chemical storage, and labeling. In the first floor space shared with the metal production company, we examined the boundary walls between the SPS room and the metal production company to identify potential contaminant pathways between the two spaces.

\section{Confidential Medical Interviews}

We asked employees about medical conditions or symptoms they thought were related to work at this facility. We took a medical history to identify unrecognized occupational illness.

\section{Beryllium Lymphocyte Proliferation Test}

The BeLPT measures how blood cells react to beryllium. We offered blood BeLPT testing for the following reasons: (1) beryllium is a sensitizer that can cause health effects at very low levels of exposure; (2) employees may have unknowingly been exposed to beryllium when they used an alloy later found to contain it; and (3) beryllium can persist in the environment until it is cleaned up.

We collected blood samples and had them analyzed at two contract laboratories. An individual with an abnormal BeLPT from both laboratories was considered sensitized to beryllium.

\section{Results and Discussion}

Few standards define acceptable levels of workplace surface contamination. Wipe samples, however, can provide information about the following:

- Effectiveness of housekeeping practices

- Potential for exposure to contaminants by dermal or oral routes (e.g., from surface contamination on a table where people eat and drink)

- Potential for contamination of worker clothing and subsequent transport of the contaminant outside the workplace or to nonproduction areas

- Potential for non-process related activities (e.g., sweeping) to generate airborne contaminants

Of the 40 wipe samples collected, four samples had detectable levels of beryllium. Figures B1-B3 in Appendix B illustrate the surface wipe sample locations and give results (positive or negative) for the SPS room, cryomilling trailer, and second floor. The limit of detection (LOD) was 0.005 micrograms per sample ( $\mu \mathrm{g} / \mathrm{sample})$. Only one of the four samples that detected beryllium (sample location: new cryomilling substrate) was above the limit of quantitation (LOQ) of $0.016 \mu \mathrm{g} / \mathrm{sample}$. This sample's beryllium level was 0.019 micrograms per 100 square centimeters $\left(\mu \mathrm{g} / 100 \mathrm{~cm}^{2}\right)$. This level is well below the United States 
Department of Energy (DOE) limit of $3 \mu \mathrm{g} / 100 \mathrm{~cm}^{2}$ for surfaces in areas with ongoing work with beryllium [DOE 1999]. This beryllium level is also below the DOE limit of $0.2 \mu \mathrm{g} / 100 \mathrm{~cm}^{2}$ for beryllium-contaminated property to be released to the public [DOE 1999].

The remaining three samples positive for beryllium were collected at the following locations:

- SPS glove box table next to the middle die press machine

- Window sill near "old" cyromilling

- Floor mat desk \#8 (see Figure 3 for desk location)

They had results between the LOD and the LOQ. One positive sample was from a nonproduction area on the second floor (under a desk in the office area). This finding indicates that contamination had spread from the production area. Beryllium levels between the LOD and the LOQ have a higher level of uncertainty associated with them.

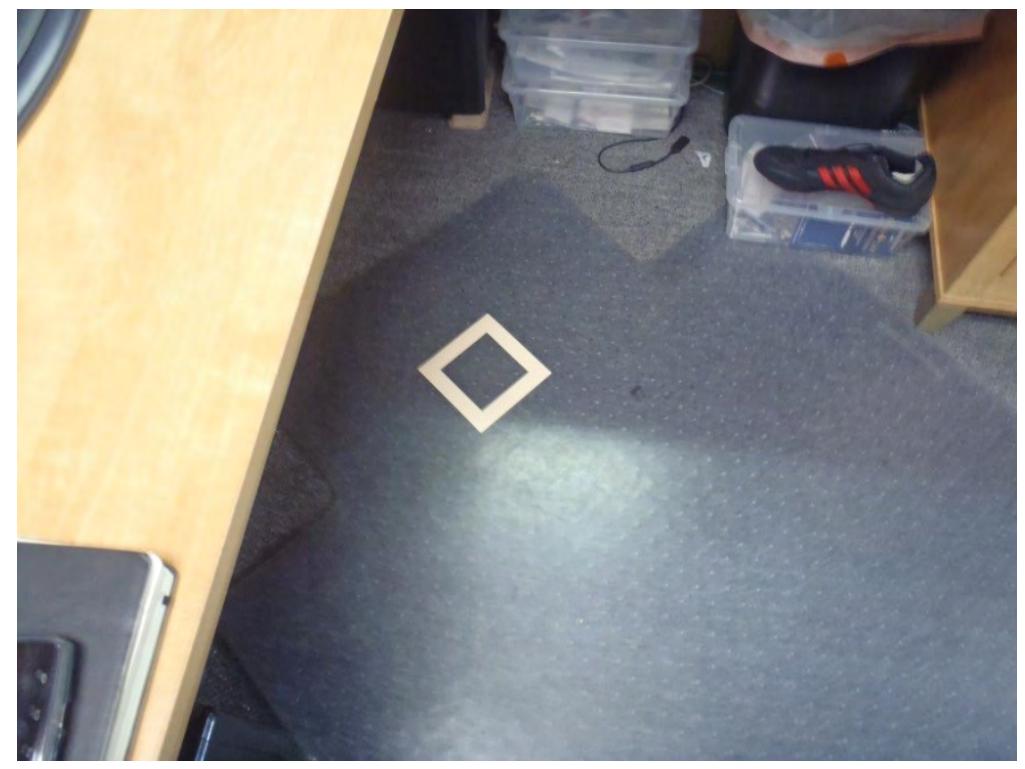

Figure 3. Surface wipe sample location in office area at desk \#8. Photo by NIOSH.

Table A1 in Appendix A lists all the surface wipe sample metals analyzed and their respective LODs and LOQs. There are no occupational exposure limits (OELs) for metals on surfaces except for the DOE beryllium standard discussed earlier.

Table 1 contains a summary of metal levels on surfaces in production and non-production areas. Non-production areas included the office and storage areas on the second floor and production included the SPS room and the cryomilling trailer. We selected the metals presented in Table 1 based on levels, number of wipe samples with detectable metals, and toxicity. 
Table 1. Levels of metals in surface wipe samples $\left(\mu \mathrm{g} / 100 \mathrm{~cm}^{2}\right)$

\begin{tabular}{|c|c|c|c|c|}
\hline \multirow[t]{2}{*}{ Metal } & \multicolumn{2}{|c|}{ Non-production (15 samples) } & \multicolumn{2}{|c|}{ Production (25 samples) } \\
\hline & $\begin{array}{c}\text { Number of } \\
\text { detectable results }\end{array}$ & Range & $\begin{array}{c}\text { Number of } \\
\text { detectable results }\end{array}$ & Range \\
\hline Beryllium & 1 & ND-0.005 & 3 & ND-0.02 \\
\hline Cadmium & 5 & ND-1.7 & 15 & ND-2.3 \\
\hline Chromium & 12 & ND-17 & 25 & $0.07-200$ \\
\hline Cobalt & 15 & $0.08-130$ & 23 & ND-18 \\
\hline Iron & 4 & ND-930 & 16 & ND-1200 \\
\hline Lead & 3 & ND-58 & 6 & ND-1.8 \\
\hline Manganese & 2 & ND-15 & 2 & ND-20 \\
\hline Nickel & 11 & ND-12 & 25 & $0.07-130$ \\
\hline Titanium & 12 & ND-18 & 22 & ND-15 \\
\hline
\end{tabular}

$\mathrm{ND}=$ Not detected

Tables A2-A4 in Appendix A include detailed information about the surface wipe samples from the SPS room, cryomilling trailer, and the second floor office area. Table A2 contains sample results from the cryomilling trailer where two of the positive beryllium surface wipe samples were taken. Table A3 contains the surface wipe sample results for the SPS room where one positive beryllium surface wipe sample was taken near the glove box. Table A4 contains the surface wipe sample results for the non-production areas on the second floor and a positive beryllium sample collected underneath an office desk.

Although metal levels were generally higher in the production area, the results from nonproduction areas indicate that metals were likely inadvertently transferred to these areas. It is important to contain metal exposures in production areas where employees have access to exposure controls. In non-production areas, employees may be exposed by consuming contaminated food and drink, having skin contact with contaminated surfaces, or inhaling metal-contaminated dust. We summarized the health effects from chronic exposure to these metals in Table A5 in Appendix A.

We did not find beryllium in the personal or area air samples. The minimum detectable beryllium concentration was 0.006 micrograms per cubic meter $\left(\mu \mathrm{g} / \mathrm{m}^{3}\right)$. We found low concentrations of chromium, cobalt, iron, nickel, and titanium in the personal air sample. Because the sample concentrations were determined based on a sampling period of less than 2 hours, the results cannot be compared to full-shift time weighted average OELs. Due to the research and development nature of this operation, SPS room activities can range from less than 1 hour per day to greater than 8 hours per day. Exposures could be different on days when the task length is different than we observed, production volume is higher, other alloys are used, or other tasks create potential metal exposures.

Table 2 lists the breathing zone air sample results for selected metals in the task-based sample collected during the die-preparation and SPS operation. Only nickel $\left(2.8 \mu \mathrm{g} / \mathrm{m}^{3}\right)$ was measured above the minimum quantifiable concentration (MQC). We listed the metals in Table 2 based upon the highest concentrations found in the air sample and their toxicity. 
Table A6 in Appendix A lists the minimum detectable concentrations (MDCs) and MQCs for all elements analyzed in the air samples.

Table 2. Concentration of selected metals in an SPS taskbased breathing zone air sample

\begin{tabular}{lc}
\hline Analyte & Air concentration $\left(\mu \mathrm{g} / \mathrm{m}^{3}\right)$ \\
\hline Beryllium & $\mathrm{ND}$ \\
Chromium & $(1.0)$ \\
Iron & $(11.3)$ \\
Nickel & 2.8 \\
Titanium & $(0.06)$ \\
\hline
\end{tabular}

${ }^{*} \mathrm{MDCs}$ and MQCs were based on an average sample volume of 0.16 cubic meter of air

$($ ) = Concentrations in parentheses are above the MDC but below the MQC, so there is more uncertainty associated with these concentrations.

The area sample collected during the die preparation and SPS operation detected only cobalt. The cobalt concentration $\left(0.3 \mu \mathrm{g} / \mathrm{m}^{3}\right)$ was between the MDC $\left(0.1 \mu \mathrm{g} / \mathrm{m}^{3}\right)$ and MQC $\left(0.5 \mu \mathrm{g} / \mathrm{m}^{3}\right)$. The transmission electron microscopy analysis found that $9 \%$ of the particles in the personal breathing zone sample were 100 nanometers or less in length, width, or diameter, which is the size definition of an engineered nanoparticle.

We measured particle counts in the SPS room and conference room during the die preparation and SPS operation. During the SPS process, particle counts in the SPS room ranged 7,000-18,000 particles per $\mathrm{cc}(\mathrm{p} / \mathrm{cc})$ of air and were lower than the particle counts in the conference room, which ranged 10,000-60,000 p/cc of air (Figure 4). Particle concentrations in the SPS room remained consistent throughout the SPS process. These results do not indicate a release associated with a specific time or task in the process during die preparation or SPS operation. 


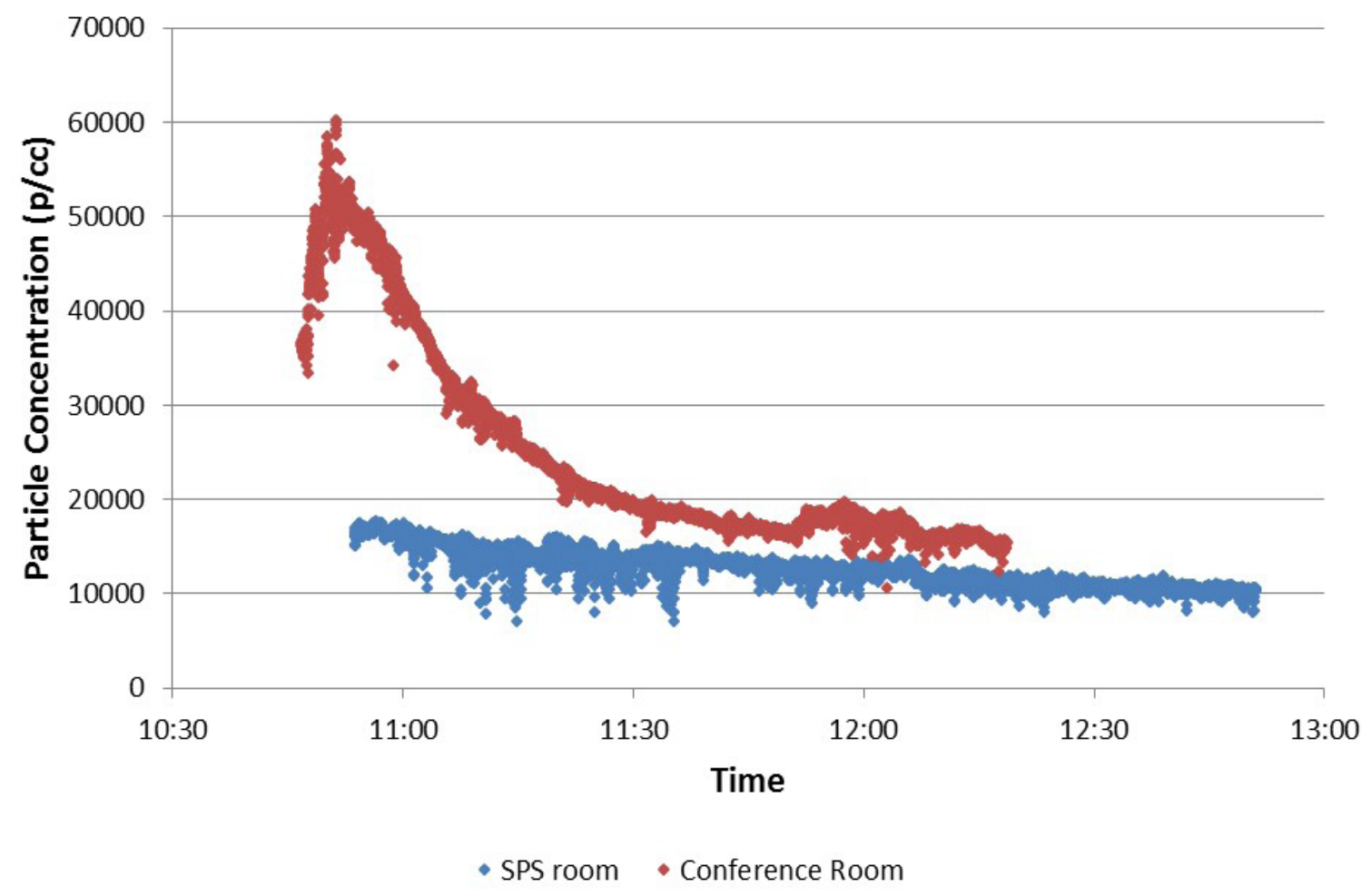

Figure 4. Particle concentrations in a production area (SPS room) and a non-production area (conference room).

The SPS room had multiple engineering controls (glove box, ventilated SPS machine, and general dilution ventilation) that controlled the production particle counts to mostly stable conditions during the sampling period. The tile flooring in the SPS room made it easier to clean and prevent the build-up of particulate. However, the conference room had only general dilution ventilation and had a high occupancy during the SPS task we evaluated. These conditions, plus the presence of carpeted flooring and fabric chairs, likely contributed to the higher particle counts.

\section{Workplace Conditions}

The production work areas were free of visible dust accumulation. We observed proper donning and doffing of PPE including respirators, gloves, laboratory coat, and safety glasses during the SPS process. The cryomilling trailer had uneven floors, potentially increasing the risk of employee slip, trip, and fall injuries.

The production and non-production areas were on separate ventilation systems. However, the first floor SPS room shared a wall with the metal production company. At numerous locations along the wall, air from the metal part production area could enter into the SPS room.

Airborne metalworking fluid, metals, and other potential hazards could easily enter migrate into the SPS. 


\section{Medical Interviews}

We interviewed all seven current and three former employees who worked at the facility when the beryllium-containing alloy was used. None reported health effects or symptoms related to work, or symptoms consistent with chronic beryllium disease.

\section{Beryllium Lymphocyte Proliferation Test}

Seven current and one former employee underwent the blood BeLPT. Another former employee reported having the BeLPT performed through a personal physician. The third former employee chose not to be tested. No tests were abnormal, meaning that none of those tested were likely sensitized to beryllium. It is believed that a person must first be sensitized before beryllium in the lungs can cause the lung damage (called granulomas) of chronic beryllium disease.

\section{Conclusions}

We found low levels of beryllium in wipe samples taken in the production and office areas. These levels were below those recommended by DOE for spaces to be occupied. Additionally, no employees were sensitized to beryllium. Surface wipe sampling indicated that current practices were insufficient in preventing inadvertent metal transfer from production to non-production areas. While the SPS operation was not considered a source nanomaterial generator, a company representative confirmed that some feedstock materials contained engineered nanomaterials. OSHA does not require that these nanomaterials be listed on an SDS if they are below the reporting requirements of less than 1 percent ( $0.1 \%$ for carcinogens) [OSHA 2016]. The company's procedures, including handling and storing nanomaterials in a glove box, using respiratory protection, and limiting access to production areas that if followed, should minimize potential employee exposures to particles generated during the SPS process.

\section{Recommendations}

On the basis of our findings, we recommend the actions listed below. We encourage the company to use a labor-management health and safety committee or working group to discuss our recommendations and develop an action plan. Those involved in the work can best set priorities and assess the feasibility of our recommendations for the specific situation at this facility.

Our recommendations are based on an approach known as the hierarchy of controls (Appendix C). This approach groups actions by their likely effectiveness in reducing or removing hazards. In most cases, the preferred approach is to eliminate hazardous materials or processes and install engineering controls to reduce exposure or shield employees. Until such controls are in place, or if they are not effective or feasible, administrative measures and PPE may be needed. 


\section{Engineering Controls}

Engineering controls reduce employees' exposures by removing the hazard from the process or by placing a barrier between the hazard and the employee. Engineering controls protect employees effectively without placing primary responsibility of implementation on the employee.

1. Evaluate the feasibility of using sticky mats at the entrance and exit to production areas to prevent metals from being unintentionally transferred to non-production areas and outside the facility on employees' footwear. If sticky mats are not feasible, the use of disposable booties or shoe change stations should also be considered.

2. Install a new barrier or modify the wall in the SPS room to separate the SPS room from the neighboring company's production floor.

\section{Administrative Controls}

The term administrative controls refers to employer-dictated work practices and policies to reduce or prevent hazardous exposures. Their effectiveness depends on employer commitment and employee acceptance. Regular monitoring and reinforcement are necessary to ensure that policies and procedures are consistently followed.

1. Advise employees who worked while beryllium-containing materials were used to alert their healthcare providers that they may have been exposed to beryllium and to share the results of their BeLPTs. If they develop respiratory symptoms, unusual fatigue, chest or joint pains, or a chronic lung disease, they should notify the healthcare provider that they may have been exposed to beryllium.

2. Perform periodic, full-shift exposure monitoring for metals when working with nanomaterials. Use the results to assess whether operating procedures and engineering controls are adequately controlling exposures.

3. Train employees on how to prevent the transfer of metals from production to nonproduction areas.

4. Ensure that employees working in production areas wash their hands after removing gloves, before leaving the production area, and before going home.

5. Repair the cryomilling work area floor to prevent slips, trips, and falls. 


\section{Appendix A: Tables}

Table A1. Analytical parameters for surface wipe samples

\begin{tabular}{lcc}
\hline Metal & LOD $(\mu \mathrm{g} / \mathrm{sample})$ & $\mathrm{LOQ}(\mu \mathrm{g} / \mathrm{sample})$ \\
\hline Arsenic & 3 & 11 \\
Barium & 0.4 & 1.4 \\
Beryllium & 0.005 & 0.02 \\
Cadmium & 0.02 & 0.08 \\
Chromium & 0.06 & 0.2 \\
Cobalt & 0.05 & 0.2 \\
Copper & 3 & 11 \\
Iron & 4 & 50 \\
Lanthanum & 0.01 & 0.04 \\
Lead & 0.2 & 0.7 \\
Manganese & 5 & 16 \\
Molybdenum & 0.09 & 0.3 \\
Nickel & 0.05 & 0.2 \\
Phosphorus & 3 & 8.5 \\
Selenium & 3 & $\mathrm{~N} / \mathrm{A}$ \\
Silver & 0.02 & 0.08 \\
Strontium & 0.02 & 0.07 \\
Tellurium & 6 & 21 \\
Tin & 2 & 5.1 \\
Titanium & 0.02 & 0.05 \\
Vanadium & 0.06 & 0.2 \\
Yttrium & 0.003 & 0.01 \\
Zinc & 8 & 50 \\
Zirconium & 0.02 & $\mathrm{~N} / \mathrm{A}$
\end{tabular}

$\mathrm{N} / \mathrm{A}=$ not applicable; selenium and zirconium did not achieve the $\mathrm{NIOSH}$ recovery criteria so an LOQ could not be established. 
Table A2. Selected elements present on surface wipe samples in the cryomilling trailer $\left(\mu \mathrm{g} / 100 \mathrm{~cm}^{2}\right)$

\begin{tabular}{|c|c|c|c|c|c|c|c|c|c|}
\hline Location & $\mathrm{Be}$ & $\mathrm{Cd}$ & $\mathrm{Cr}$ & Co & $\mathrm{Fe}$ & $\mathrm{Pb}$ & $\mathrm{Mn}$ & $\mathrm{Ni}$ & $\mathrm{Ti}$ \\
\hline \multicolumn{10}{|l|}{ New cryomill } \\
\hline Substrate & 0.02 & 0.34 & 4.7 & 1.5 & 71 & $(0.25)$ & ND & 6.4 & 1.9 \\
\hline Floor & ND & 2.3 & 13 & 6.9 & 250 & $(0.43)$ & ND & 16 & 3.2 \\
\hline \multicolumn{10}{|l|}{ Old cryomill } \\
\hline Inside containment & ND & $(0.08)$ & 2.3 & 0.83 & (13) & ND & ND & 2.3 & 0.35 \\
\hline Floor & ND & 1.3 & 3.7 & 1.8 & 41 & 0.22 & ND & 8.5 & 1.2 \\
\hline \multicolumn{10}{|l|}{ Cryomill trailer } \\
\hline Window sill \#1 & $(0.007)$ & $(0.08)$ & 24 & 15 & 63 & ND & ND & 130 & 0.68 \\
\hline Window sill \#2 & ND & 0.37 & 100 & 15 & 710 & 1.5 & 16 & 55 & 15 \\
\hline Floor (glove box) & ND & 0.22 & 5.0 & 2.0 & $(50)$ & ND & ND & 4.5 & 0.15 \\
\hline $\begin{array}{l}\text { Table near } \\
\text { corkboard }\end{array}$ & ND & ND & 1.1 & 4.8 & 4.8 & ND & ND & 0.85 & 0.16 \\
\hline Ductwork & ND & ND & $(0.19)$ & $(0.06)$ & ND & ND & ND & 0.26 & 0.06 \\
\hline Electrical panel & ND & $(0.02)$ & $(0.13)$ & ND & ND & ND & ND & $(0.17)$ & 0.12 \\
\hline Long-term storage & ND & ND & $(0.07)$ & ND & ND & ND & ND & $(0.09)$ & ND \\
\hline New addition floor & ND & 0.34 & 200 & 8.7 & 1200 & 1.8 & 20 & 91 & 5.6 \\
\hline
\end{tabular}

Table A3. Selected elements present on surface wipe samples in the SPS room $\left(\mu \mathrm{g} / 100 \mathrm{~cm}^{2}\right)$

\begin{tabular}{|c|c|c|c|c|c|c|c|c|c|}
\hline Location & $\mathrm{Be}$ & $\mathrm{Cd}$ & $\mathrm{Cr}$ & Co & $\mathrm{Fe}$ & $\mathrm{Pb}$ & $\mathrm{Mn}$ & $\mathrm{Ni}$ & $\mathrm{Ti}$ \\
\hline \multicolumn{10}{|l|}{ Workbench } \\
\hline Near die prep & ND & ND & 0.21 & 1.7 & (5.3) & ND & ND & $(0.24)$ & 0.16 \\
\hline Near die press & ND & $(0.05)$ & 2.1 & 18 & ND & ND & ND & 1.6 & 0.53 \\
\hline Next to sink & ND & 0.5 & 0.41 & 2.6 & $(20)$ & ND & ND & $(0.54)$ & 0.20 \\
\hline \multicolumn{10}{|l|}{ Glove box } \\
\hline Area near opening & ND & ND & $(0.16)$ & 0.39 & ND & ND & ND & 0.48 & ND \\
\hline Table & $(0.007)$ & ND & 0.56 & 2.7 & $(40)$ & ND & ND & 1.4 & ND \\
\hline \multicolumn{10}{|l|}{ SPS } \\
\hline Side panel & ND & ND & $(0.08)$ & $(0.1)$ & ND & ND & ND & $(0.07)$ & $(0.03)$ \\
\hline Horizontal substrate & ND & ND & 0.22 & 0.7 & ND & ND & ND & 0.33 & 0.26 \\
\hline Floor in front of SPS & ND & $(0.03)$ & 1.0 & 3.3 & $(49)$ & ND & ND & 1.3 & 0.82 \\
\hline Floor (side of SPS) & ND & ND & 1.2 & 2.0 & $(32)$ & ND & ND & 1.4 & 0.77 \\
\hline $\begin{array}{l}\text { Side door (to adjacent } \\
\text { company) }\end{array}$ & ND & $(0.02)$ & 0.36 & 0.9 & ND & ND & ND & $(0.93)$ & 0.47 \\
\hline Side door knob & ND & 0.24 & 2.6 & 1.9 & $(25)$ & ND & ND & 3.0 & 0.40 \\
\hline $\begin{array}{l}\text { Top of flammable } \\
\text { cabinet }\end{array}$ & ND & ND & 1.1 & 0.42 & ND & ND & ND & $(0.2)$ & 0.09 \\
\hline Corner floor near SPS & ND & 0.13 & 3.1 & 2.8 & 110 & 0.78 & ND & 6.0 & 2.6 \\
\hline
\end{tabular}


Table A4. Selected elements present on surface wipe samples in the office area $\left(\mu \mathrm{g} / 100 \mathrm{~cm}^{2}\right)$

\begin{tabular}{|c|c|c|c|c|c|c|c|c|c|}
\hline Location & $\mathrm{Be}$ & $\mathrm{Cd}$ & $\mathrm{Cr}$ & Co & $\mathrm{Fe}$ & $\mathrm{Pb}$ & $\mathrm{Mn}$ & $\mathrm{Ni}$ & $\mathrm{Ti}$ \\
\hline \multicolumn{10}{|l|}{ Conference room } \\
\hline Cabinet top & ND & 1.7 & 17 & 130 & 930 & 58 & $(15)$ & 12 & 13 \\
\hline Book shelf & ND & 0.5 & 5.1 & 27 & 420 & 14 & $(5.7)$ & 4.4 & 18 \\
\hline Conference table & ND & ND & ND & $(0.08)$ & ND & ND & ND & ND & ND \\
\hline \multicolumn{10}{|l|}{ Desk \#1 } \\
\hline Next to mouse & ND & ND & $(0.08)$ & 0.27 & ND & ND & ND & $(0.15)$ & 0.06 \\
\hline Floor under desk & ND & ND & 0.36 & $(0.19)$ & ND & $(0.29)$ & ND & 0.19 & 0.15 \\
\hline \multicolumn{10}{|l|}{ Desk \#2 } \\
\hline Next to mouse & ND & ND & $(0.19)$ & 1.3 & ND & ND & ND & $(0.17)$ & 0.08 \\
\hline Floor under desk & ND & $(0.02)$ & 0.22 & 1.2 & $(4.6)$ & ND & ND & $(0.12)$ & 0.22 \\
\hline \multicolumn{10}{|l|}{ Desk \#3 } \\
\hline Next to mouse & ND & ND & $(0.19)$ & 0.67 & ND & ND & ND & 0.42 & 0.12 \\
\hline Floor under desk & ND & $(0.05)$ & $(0.08)$ & 0.36 & ND & ND & ND & $(0.08)$ & 0.17 \\
\hline \multicolumn{10}{|l|}{ Desk \#5 } \\
\hline Next to mouse & ND & ND & $(0.13)$ & $(0.14)$ & ND & ND & ND & $(0.07)$ & ND \\
\hline Floor under desk & ND & $(0.04)$ & ND & $(0.11)$ & ND & ND & ND & ND & $(0.04)$ \\
\hline \multicolumn{10}{|l|}{ Desk \#6 } \\
\hline Next to mouse & ND & ND & $(0.09)$ & $(0.11)$ & ND & ND & ND & 0.10 & $(0.04)$ \\
\hline Floor under desk & ND & ND & 0.29 & 0.49 & $(18)$ & ND & ND & $(0.12)$ & 0.29 \\
\hline \multicolumn{10}{|l|}{ Desk \#8 } \\
\hline Next to mouse & ND & ND & ND & $(0.17)$ & ND & ND & ND & ND & ND \\
\hline Floor under desk & $(0.005)$ & ND & $(0.07)$ & 0.25 & ND & ND & ND & ND & 0.12 \\
\hline
\end{tabular}

() = Concentrations in parentheses are above the LOD but below the LOQ, so there is more uncertainty associated with these levels. 
Table A5. Summary of health effects and cancer classifications for selected metals found in the facility

\begin{tabular}{ll}
\hline Metal & \multicolumn{1}{c}{ Health effects of chronic, low-level exposure } \\
\hline Beryllium & Sensitization, chronic beryllium disease \\
Cadmium & $\begin{array}{l}\text { Kidney damage, respiratory irritation, chronic } \\
\text { obstructive lung disease }\end{array}$ \\
$\begin{array}{l}\text { Chromium } \\
\text { (elemental } \\
\text { and } \\
\text { hexavalent) }\end{array}$ & $\begin{array}{l}\text { Skin irritation and ulceration, allergic contact dermatitis, } \\
\text { respiratory irritation, chronic lung disease, nasal septal } \\
\text { perforation }\end{array}$ \\
\end{tabular}

Cobalt Lung damage from exposure to cobalt-tungsten carbide alloy. Irritant and allergic contact dermatitis
Iron $\quad$ Siderosis, a usually benign lung condition
Lead Neurological (tremor, psychiatric effects, decreased (inorganic) hearing, decreased cognitive function, increased risk of amyotrophic lateral sclerosis), increased blood pressure and hypertensions, decreased kidney function reproductive (reduced fetal growth, spontaneous abortion, preterm birth, abnormal sperm parameters), and decreased kidney function
Manganese Subclinical neurological effects, such as decreased performance on neurobehavioral tests; significantly poorer eye-hand coordination, hand steadiness, and reaction time; poorer postural stability; and lower levels of cognitive flexibility

Nickel Allergic contact dermatitis, respiratory irritation, chronic bronchitis, asthma, reduced lung function

Nickel compounds, Group 1: carcinogenic to humans; paranasal sinus, nasal cavity, and lung.

Titanium Eye and respiratory irritation

Group 2B:

possibly carcinogenic to humans 
Table A6. Air sample minimum detectable and quantifiable concentrations

\begin{tabular}{lcc}
\hline Metal & $\mathrm{MDC}^{*}\left(\mu \mathrm{g} / \mathrm{m}^{3}\right)$ & $\mathrm{MQC}^{*}\left(\mu \mathrm{g} / \mathrm{m}^{3}\right)$ \\
\hline Arsenic & 2.5 & 7.6 \\
Barium & 1.9 & 6.2 \\
Beryllium & 0.01 & 0.02 \\
Cadmium & 0.2 & 0.6 \\
Chromium & 0.6 & 2.0 \\
Cobalt & 0.1 & 0.5 \\
Copper & 0.6 & 2.4 \\
Iron & 6.3 & 23 \\
Lanthanum & 0.2 & 0.6 \\
Lead & 0.6 & 3.2 \\
Manganese & 0.5 & 1.6 \\
Molybdenum & 0.6 & 1.8 \\
Nickel & 0.6 & 1.8 \\
Phosphorus & 4.4 & 14 \\
Selenium & 13 & 43 \\
Silver & 0.1 & 0.3 \\
Strontium & 0.03 & 0.11 \\
Tellurium & 1.3 & 4.9 \\
Tin & 0.6 & 2.9 \\
Titanium & 0.06 & 0.2 \\
(dioxide) & & 1.6 \\
Vanadium & 0.5 & 0.05 \\
Yttrium & 0.01 & 9.5 \\
Zinc & 2.5 & \\
Zirconium & 0.3 & \\
\hline *MDs & 0.1 \\
\hline
\end{tabular}

${ }^{*} \mathrm{MDCs}$ and MQCs were based on an average sample volume of 0.16 cubic meters of air. 


\section{Appendix B: Figures}

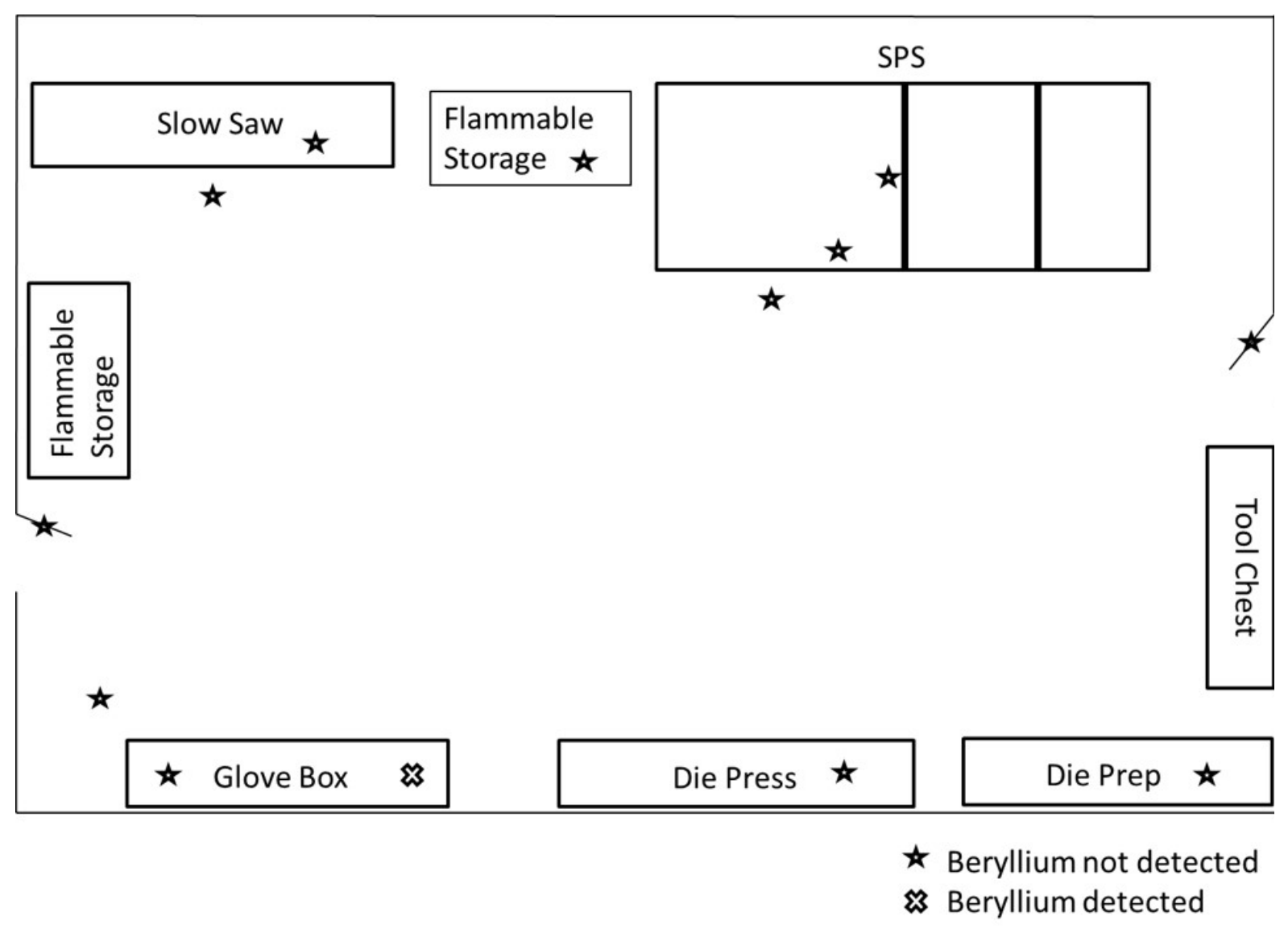

Figure B1. SPS room surface wipe sample locations 


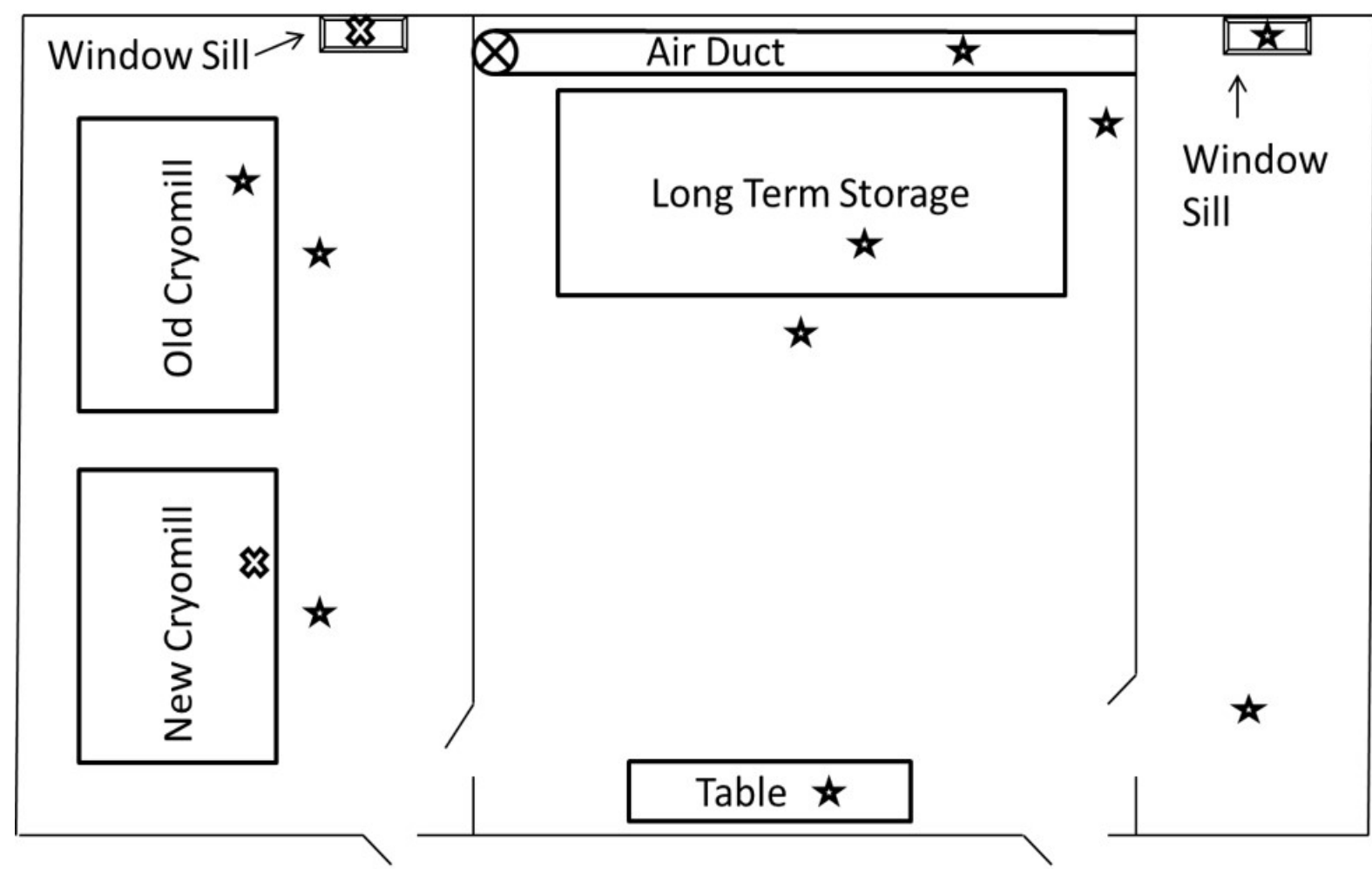

* Beryllium not detected

« Beryllium detected

Figure B2. Cryomilling trailer surface wipe sample locations 

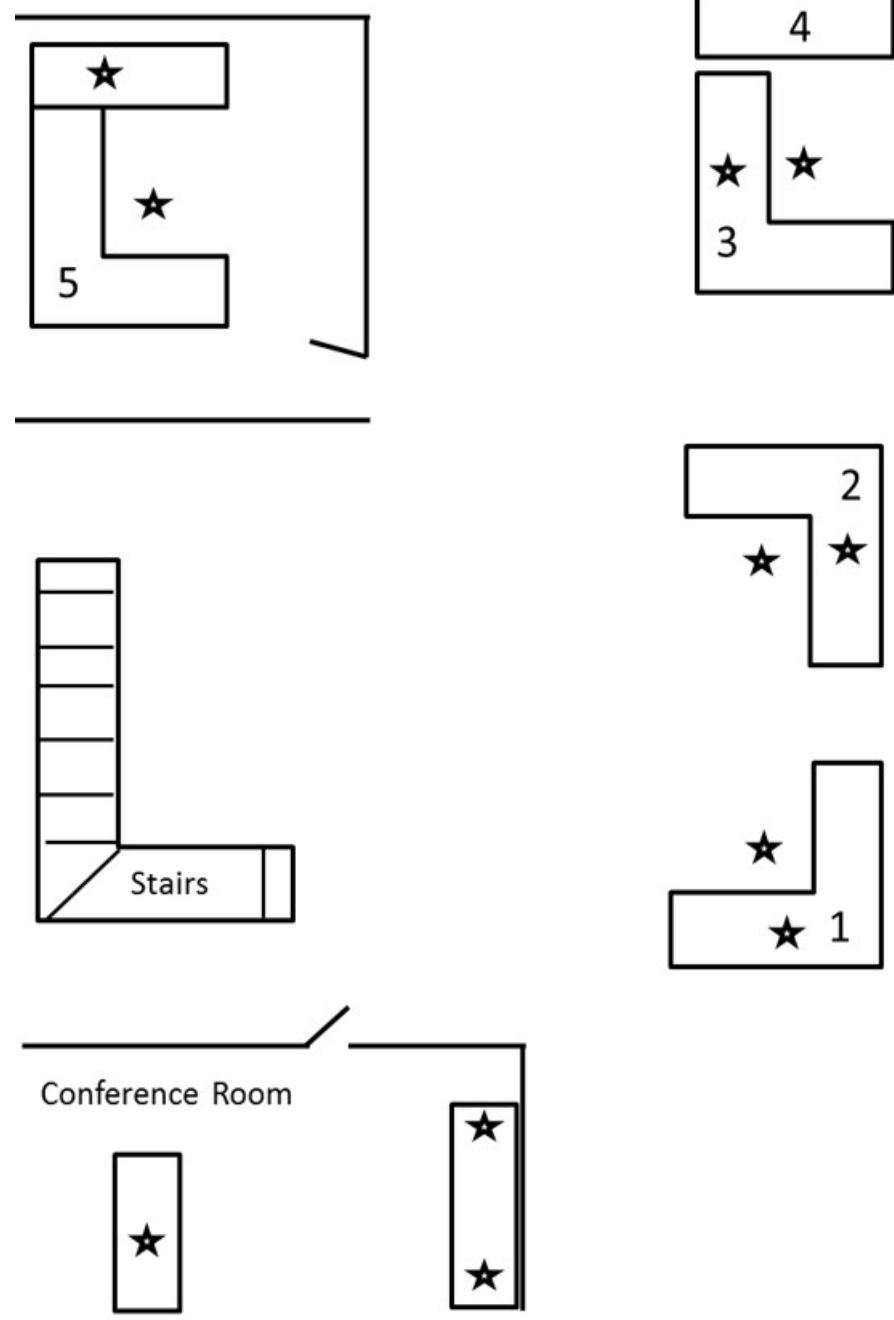

Figure B3. Second floor surface wipe sample locations

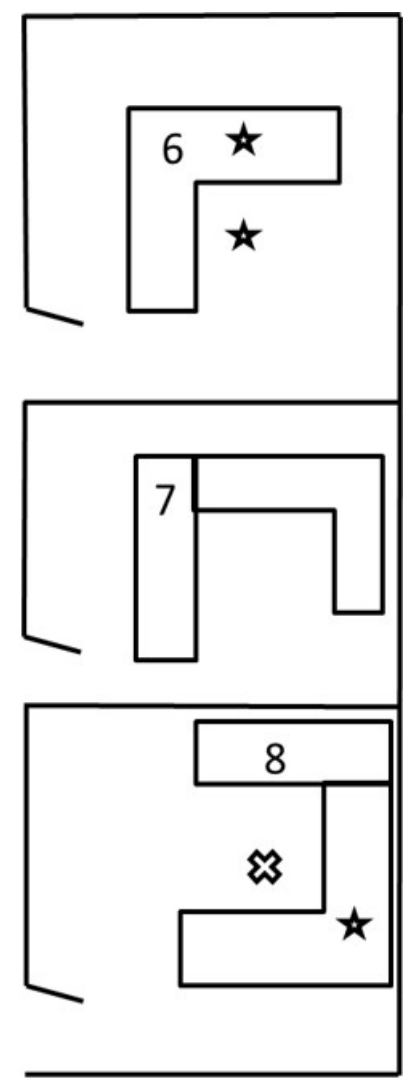

$\star$ Beryllium not detected

« Beryllium detected 


\section{References}

AIHA [2015]. AIHA 2015 Emergency response planning guidelines (ERPG) \& workplace environmental exposure levels (WEEL) handbook. Fairfax, VA: American Industrial Hygiene Association.

CFR. Code of Federal Regulations. Washington, DC: U.S. Government Printing Office, Office of the Federal Register.

DOE [1999]. Chronic beryllium disease prevention program. 10 CFR Part 850 [Docket No. EH-RM-98-BRYLM] RIN 1901-AA75. Office of Environment, Safety, and Health, Department of Energy. Final Rule. Federal Register, Vol. 64, No. 235, Wednesday, December 8, 1999, Rules and Regulations, pp. 68854-68914. [https://www.gpo.gov/fdsys/pkg/FR-199912-08/pdf/99-31181.pdf]. Date accessed: March 2016.

Fuji [2016]. What's SPS. Fuji Electronic Industrial Company. [http://sps.fdc.co.jp/whats/]. Date accessed: March 2016.

IARC [2016]. International Agency for Research on Cancer monographs on the evaluation of carcinogenic risks to humans. [http://monographs.iarc.fr/ENG/Classification/]. Date accessed: March 2016.

NIOSH [2010]. NIOSH pocket guide to chemical hazards. Cincinnati, OH: U.S. Department of Health and Human Services, Centers for Disease Control and Prevention, National Institute for Occupational Safety and Health, DHHS (NIOSH) Publication No. 2010-168c. [http://www.cdc.gov/niosh/npg/]. Date accessed: March 2016.

NIOSH [2016]. NIOSH manual of analytical methods (NMAM®). 4th ed. Schlecht PC, O'Connor PF, eds. Cincinnati, OH: U.S. Department of Health and Human Services, Centers for Disease Control and Prevention, National Institute for Occupational Safety and Health, DHHS (NIOSH) Publication 94-113 (August 1994); 1st Supplement Publication 96-135; 2nd Supplement Publication 98-119; 3rd Supplement 2003-154. [http://www.cdc.gov/niosh/ docs/2003-154/].

OSHA [2016]. Comparison of hazard communication requirements. Occupational Safety and Health Administration. [https://www.osha.gov/dsg/hazcom/docs/ghsoshacomparison.pdf]. Date accessed: March 2016. 
Keywords: North American Industry Classification System 541711 (Research and Development in Biotechnology), chemical, California, beryllium, BeLPT, nanotechnology, nanoparticle, metals, surface wipe sample 
This page left intentionally blank 
The Health Hazard Evaluation Program investigates possible health hazards in the workplace under the authority of the Occupational Safety and Health Act of 1970 (29 U.S.C. § 669(a) (6)). The Health Hazard Evaluation Program also provides, upon request, technical assistance to federal, state, and local agencies to investigate occupational health hazards and to prevent occupational disease or injury. Regulations guiding the Program can be found in Title 42, Code of Federal Regulations, Part 85; Requests for Health Hazard Evaluations (42 CFR Part 85).

\section{Disclaimer}

The recommendations in this report are made on the basis of the findings at the workplace evaluated and may not be applicable to other workplaces.

Mention of any company or product in this report does not constitute endorsement by NIOSH.

Citations to Web sites external to NIOSH do not constitute NIOSH endorsement of the sponsoring organizations or their programs or products. NIOSH is not responsible for the content of these Web sites. All Web addresses referenced in this document were accessible as of the publication date.

\section{Acknowledgments}

Analytical Support: National Jewish Health, Oak Ridge Institute for Science and Education, Bureau Veritas North America

Desktop Publisher: Shawna Watts

Editor: Ellen Galloway

Industrial Hygiene Field Assistance: Emily Lee

Logistics: Donnie Booher, Kevin Moore

Medical Field Assistance: Deborah Sammons

\section{Availability of Report}

Copies of this report have been sent to the employer and employees at the facility. The state and local health department and the Occupational Safety and Health Administration Regional Office have also received a copy. This report is not copyrighted and may be freely reproduced.

This report is available at http://www.cdc.gov/niosh/hhe/reports/pdfs/2014-0207-3248.pdf.

\section{Recommended citation for this report:}

NIOSH [2016]. Health hazard evaluation report: evaluation of metal exposure at a nanoparticle research and development company. By Couch J, Page E, Dunn K. Cincinnati, OH: U.S. Department of Health and Human Services, Centers for Disease Control and Prevention, National Institute for Occupational Safety and Health, NIOSH HHE Report No. 2014-0207-3248. 
Delivering on the Nation's promise:

Safety and health at work for all people through research and prevention

To receive NIOSH documents or more information about occupational safety and health topics, please contact NIOSH:

Telephone: 1-800-CDC-INFO (1-800-232-4636)

TTY: 1-888-232-6348

CDC INFO: www.cdc.gov/info

or visit the NIOSH Web site at www.cdc.gov/niosh

For a monthly update on news at $\mathrm{NIOSH}$, subscribe to

$\mathrm{NIOSH}$ eNews by visiting www.cdc.gov/niosh/eNews. 